\title{
Galectin-3 as a potential biomarker of metabolic disorders and cardiovascular remodeling in patients with hypertension and type 2 diabetes
}

\author{
Lesya Bobronnikova \\ Department of Clinical Pharmacology, Kharkiv National Medical University, 61000 Kharkiv, Ukraine.
}

Correspondence to: Prof. Lesya Bobronnikova, Head of Department of Clinical Pharmacology, Kharkiv National Medical University, 2A Postysheva Avenue, 61000 Kharkiv, Ukraine. E-mail: 1.bobronnikova@mail.ru

How to cite this article: Bobronnikova L. Galectin-3 as a potential biomarker of metabolic disorders and cardiovascular remodeling in patients with hypertension and type 2 diabetes. Vessel Plus 2017;1:61-7.

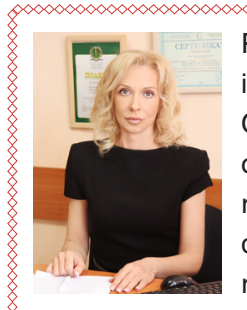

Prof. Lesya Bobronnikova received her doctorate in 2009. She is an author and co-author of publications in international journals on metabolic syndrome, hypertension and diabetes. Currently, she is Head of the Department of Clinical Pharmacology at the Kharkov National Medical University, the clinical basis of which is located on the territory of the L. T. Malaya National Therapy Institute of NAMS of Ukraine. At the moment, the department is involved in research work on optimization of diagnosis and treatment of combined arterial hypertension and gene polymorphism dependent diabetes mellitus type 2. Prof. Lesya Bobronnikova invites all scientists interested in the subject of our research work for international cooperation.
Article history:

Received: 26-10-2016

Accepted: 08-05-2017

Published: 27-06-2017

\section{Key words:}

Arterial hypertension, type 2 diabetes mellitus, insulin resistance, cardiovascular remodeling, galectin-3

\begin{abstract}
Aim: To determine the impact of galectin-3 levels on the progression of metabolic disorders and structural-functional changes in the myocardium and blood vessels in patients with concomitant systemic arterial hypertension (AH) and type 2 diabetes mellitus (type $2 \mathrm{DM}$ ). Methods: Ninety-five patients with hypertension stage II grade 2 (53 males and 42 females) were examined. The patients were separated: group $1(n=32)$ patients with AH, without carbohydrate metabolism disorders; group $2(n=30)$ patients with AH and pre-diabetes; group $3(n=33)$ concomitant $\mathrm{AH}$ and type 2 DM. Carbohydrate metabolism, insulin resistance parameters and galectin-3 levels were measured. Echocardiography was performed to determine the structural-functional condition of the heart. Estimation of the intima-media complex thickness of the common carotid artery was performed by duplex ultrasound scanning. Results: Hypertrophy of the left ventricular myocardium is most evident in patients with $\mathrm{AH}$ and type 2 DM compared with groups 1 and 2 , and the control group $(P<0.05)$. The levels of galectin-3 in the group with concomitant hypertension and type $2 \mathrm{DM}$ were higher than in groups 1 and 2 , and the control group $(P<0.05)$. A positive correlation was revealed between the level of galectin-3, indices of insulin resistance, and structural-functional cardiac and vessel remodeling. Conclusion: Galectin-3 levels in serum are significantly linked with indices of insulin resistance and cardiovascular remodeling.
\end{abstract}

\section{(c) (i)} icer and reproduction in identical terms.

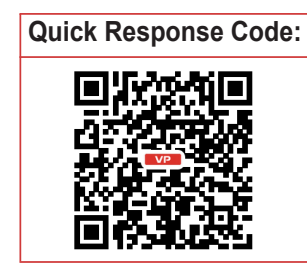




\section{INTRODUCTION}

Despite the appreciable advancement in arterial hypertension $(\mathrm{AH})$ prevention and treatment, the disease remains to be one of the most urgent problems in cardiology. ${ }^{[1]}$ Commonly, $\mathrm{AH}$ accompanies prediabetes and type 2 diabetes mellitus (type $2 \mathrm{DM}$ ), important risk factors for cardiovascular complications.

Chronic hyperglycemia in $\mathrm{AH}$ patients with glucose metabolism disorders and type 2 DM significantly contributes to the formation and progression of cardiovascular disease. ${ }^{[2]}$ Carbohydrate metabolism disorders significantly increase risk of acute cardiovascular events, such as myocardial infarction. ${ }^{[3]}$ A meta-analysis of large prospective studies encompassing a total of 450,000 selected patients demonstrated that the risk of coronary death is increased 2-3 fold in patients with diabetes. ${ }^{[4]}$ Chronic hyperglycemia not only directly promotes myocardial lesions, but also exacerbates the negative effect of other risk factors for cardiovascular pathology. ${ }^{[5]}$ It has been noted that the degree of impairment in myocardial diastolic properties directly depends on the level of glycated hemoglobin, which relates to the degree of myocardium protein glycation ${ }^{[6]}$ and deposition of collagen in the myocardium with fibrosis. ${ }^{[7]}$ Furthermore, it is known that patients with carbohydrate metabolism disorders have higher left ventricular (LV) mass, even in the absence of $\mathrm{AH}$ and heart disease. ${ }^{[8]}$

Recently, new biomarkers that may reflect the pathogenic process of insulin resistance and consequent cardiovascular events have been identified. One of those markers is galectin-3 (Gal-3). ${ }^{\left[{ }^{[9]}\right.}$ It belongs to the $\beta$-galactoside-binding proteins family. Due to the presence of a collagenous domain in its structure, galectin can interact with a wide range of extracellular matrix proteins such as tenascin, fibronectin, and laminin ${ }^{[10]} \mathrm{Gal}-3$ is produced by numerous cells including neutrophils, macrophages, labrocytes, fibroblasts, and osteoclasts. ${ }^{[11]} \mathrm{Gal}-3$ is found in lungs, stomach, intestine and uterus. ${ }^{[12]}$ It was determined that Gal-3 is involved in proliferation, macrophage chemotaxis, phagocytosis, neutrophil transudation, oxidative stress, apoptosis, angiogenesis, and associated with the development of insulin resistance. ${ }^{[13,14]}$ In experimental studies using different models of cardiovascular disease, Gal3 has been implicated as an inducer of fibrosis and myocardial remodeling. ${ }^{[15,16]}$

Recently, a single-case study demonstrated Gal-3 as a mediator of development and progression of cardiac hypertrophy in patients with AH. ${ }^{[17]}$ There are also data describing its impact on the formation of diastolic myocardial dysfunction. ${ }^{[18]}$
The role of Gal-3 has not yet been examined in large cohorts of $\mathrm{AH}$ and type $2 \mathrm{DM}$ patients, but according to single-case studies the plasma Gal-3 levels correlate with the prevalence of type $2 \mathrm{DM}, \mathrm{AH}$ and obesity. ${ }^{[19,20]}$

Thus, the goal of determining the effect of this biomarker on the progression of dysglycemia and cardiovascular remodeling in patients with $\mathrm{AH}$ and comorbid type $2 \mathrm{DM}$ is attracting considerable interest in clinical practice.

The experiments herein studied the effect of Gal-3 levels on the progression of metabolic disorders and structural-functional changes in the myocardium and blood vessels of patients with concomitant $\mathrm{AH}$ and type 2 DM.

\section{METHODS}

Ninety-five patients with hypertension stage II grade 2 (53 males and 42 females) were examined in the specialized Department of Arterial Hypertension and Kidney Disease of State Institution (National Institute of Therapy named after L.T. Malaya) of National Academy of Medical Sciences of Ukraine. The patients were distributed into the following groups: group 1 ( $n$ = 32) included patients with $\mathrm{AH}$, without carbohydrate metabolism disorders; group $2(n=30)$, patients with $\mathrm{AH}$ and pre-diabetes; group $3(n=33)$, concomitant $\mathrm{AH}$ and type $2 \mathrm{DM}$. The control group $(n=20)$ was comparable by age and gender to each group of examined patients. All the patients signed an informed consent agreement to participate in the research.

The exclusion criteria included the presence of severe somatic diseases such as kidney, liver, heart, and respiratory failure, anamnestic evidence of stroke, myocardial infarction, oncological diseases, decompensated type 2 DM course according to World Health Organization criteria, female patients previously diagnosed with type 2 DM macrovascular complications, thyroid function disorders, primary familial hypercholesterolemia, secondary hypertensions, and pregnancy.

$\mathrm{AH}$ diagnostics were performed according to the recommendations of the European Society of Hypertension and the European Society of Cardiology (ESH/ESC, 2013), as well as the Ukrainian Association of Cardiology on prevention and treatment of hypertension (2013). Anthropometric measurements included the calculation of body mass index (BMI) and the degree of obesity according to the International Diabetes Federation criteria (2015). Type 2 DM was diagnosed according to the general recommendations of the European Association for the Study of Diabetes 
(EASD, 2013).

Glycated hemoglobin (HbA1c) levels in whole blood were measured using the test-system produced by Reagent (Ukraine). Homeostatic model assessment for insulin resistance (HOMA-IR) was calculated by the formula: HOMA-IR = insulin (fasting insulin, $\mathrm{mcU} / \mathrm{mL}$ ) $\times$ fasting glucose $(\mathrm{mmol} / \mathrm{L}) / 22.5$. At HOMA-IR > 2.77 patients were considered as having insulin resistance. ${ }^{[21]}$ C-reactive protein (CRP) - DRG Elisa were determined with Enzyme-Linked ImmunoSorbent Assay (ELISA).

The concentrations of fasting blood glucose (FBG) levels was determined using glucose oxidase methodology. Fasting serum insulin levels were determined by ELISA with DRG kit (USA). In order to determine glucose tolerance, an oral glucose tolerance test was performed.

Gal-3 levels in the serum were determined by ELISA using the kit of Bender Med Systems (Austria).

Structural-functional cardiac parameters were determined by echocardiography using the diagnostic system (Philips IU, USA) in B-and M-modes by standard technique according to the general recommendations of the American Society of Echocardiography (2015). The determination of the interventricular septal wall thickness, LV posterior wall, end-systolic dimension (ESD), end-diastolic dimension (EDD), LV ejection fraction; end-systolic volume (ESV), end-diastolic volume (EDV); and analysis of the LV diastolic function were conducted during the registration of transtricuspid diastolic flow in the pulsed-wave Doppler mode. LV myocardial mass (LVMM) was calculated using the formula of Devereux R.B. (1986) and the index of LVMM (LVMMI) was determined as the ratio of LVMM to body surface area as described by Brown D.W. (2000).

To assess the structural-functional state of the vessels we performed ultrasound scanning of common carotid arteries with measurement of the intima-media complex thickness of the common carotid artery (IMT CCA) using an ultrasound diagnostic system (Philips IU, USA) with linear sensor at the frequency of at least $7 \mathrm{MHz}$ in B-mode.

As soon as the distribution of indices were converted to the normal, statistical processing of obtained results was performed by parametric methods (with evaluation of mean, its standard error or standard deviation; Student $t$-test for independent samples by groups, Pearson correlation) using Statsoft Statistica 8.0 software package. The threshold of $P$-value of
0.05 was chosen; in case of multiple comparison a Bonferroni correction was made.

\section{RESULTS}

The results of trophological status analysis revealed characteristic features in the examined groups. Patients with a BMI of 18.5 to $24.9 \mathrm{~kg} / \mathrm{m}^{2}(n=5)$ were identified in the group with isolated $\mathrm{AH}$. However third-degree obesity (BMI $>40.0 \mathrm{~kg} / \mathrm{m}^{2}$ ) was observed in one patient with $\mathrm{AH}$, in three patients with $\mathrm{AH}$ and pre-diabetes, and in 5 patients with concomitant $\mathrm{AH}$ and type $2 \mathrm{DM}$. The majority of patients with isolated and concomitant disease in groups 2 and $3(64.2 \%, 54.3 \%$, and $51.3 \%$ respectively) had a BMI of 30 to $34.9 \mathrm{~kg} / \mathrm{m}^{2}$. In patients with type $2 \mathrm{DM}$, those with a BMI of 30.0 to $34.9 \mathrm{~kg} / \mathrm{m}^{2}$ were predominately male $(67.3 \%)$, while those with a BMI of 35.0 to $39.9 \mathrm{~kg} / \mathrm{m}^{2}$ were predominately female (74.5\%).

FBG levels were significantly higher in patients with concomitant $\mathrm{AH}$ and type $2 \mathrm{DM}$ compared with patients in group 1, group 2 and the control group $(P<0.05)$.

Maximal values of HOMA-IR, insulin and C-peptide in patients of group 3 compared to that of groups 1 and 2 [Table 1], describes the progression of IR associated with the presence of type 2 diabetes. HOMA-IR exceeded control values by 2.1 -fold in the group of patients with $\mathrm{AH}, 2.4$-fold in patients with $\mathrm{AH}$ and pre-diabetes, and by 2.7 -fold higher in patients with concomitant $\mathrm{AH}$ and type $2 \mathrm{DM}$.

In groups 2 and 3 , there was a positive correlation between insulin levels in the peripheral blood and LV hypertrophy $(\mathrm{LVH})(r=0.44, P<0.01$; and $r=0.42, P$ $<0.01$, respectively) and IMT CCA $(r=0.36, P<0.05$; and $r=0.38, P<0.05$, respectively).

Examination of IMT CCA showed mean values in patients with $\mathrm{AH}(0.85 \pm 0.05 \mathrm{~mm}, P<0.05)$ in comparison with groups 2 and 3 , and control group. In patients with $\mathrm{AH}$ and pre-diabetes this index was 0.9 $\pm 0.05 \mathrm{~mm}(P<0.05)$. In patients with $\mathrm{AH}$ and type 2 diabetes IMT CCA was $0.95 \pm 0.07 \mathrm{~mm}(P<0.05)$. IMT CCA indices in groups 2 and 3 displayed reverse correlation with HOMA-IR $(r=0.36, P<0.001)$.

An increase of IMT CCA $\geq 0.9 \mathrm{~mm}$ was observed in patients with $\mathrm{AH}$ in $46.8 \%$ of cases, $52.7 \%$ in patients with $\mathrm{AH}$ and pre-diabetes, and $59.2 \%$ in patients with concomitant disease.

Indices of IMT CCA were associated with age $(P=$ 0.032), BMI $(P=0.044)$, waist measurements $(P=$ 
Table 1: Carbohydrate metabolism and IR indices in surveyed groups of patients (mean \pm SD)

\begin{tabular}{|c|c|c|c|c|c|}
\hline Indices & $\begin{array}{l}\text { 1. Control } \\
(n=20)\end{array}$ & $\begin{array}{c}\text { 2. AH } \\
(n=32)\end{array}$ & $\begin{array}{l}\text { 3. AH + pre-diabetes } \\
(n=30)\end{array}$ & $\begin{array}{c}\text { 4. AH + type } 2 \mathrm{DM} \\
(n=33)\end{array}$ & $\boldsymbol{P}$ \\
\hline HOMA-IR & $1.66 \pm 0.56$ & $3.46 \pm 2.70$ & $4.46 \pm 2.70$ & $5.42 \pm 3.10$ & $\begin{array}{l}P_{1-2}=0.00001 \\
P_{1-3}=0.00001 \\
P_{2-3}=0.13\end{array}$ \\
\hline Insulin, $\mathrm{mcU} / \mathrm{mL}$ & $5.57 \pm 2.10$ & $10.90 \pm 5.80$ & $11.90 \pm 5.80$ & $13.80 \pm 7.40$ & $\begin{array}{l}P_{1-2}=0.0004 \\
P_{1-3}=0.0002 \\
P_{2-3}=0.049\end{array}$ \\
\hline CRP, ng/mL & $0.48 \pm 0.23$ & $0.94 \pm 0.53$ & $1.02 \pm 0.41$ & $1.20 \pm 0.73$ & $\begin{array}{l}P_{1-2}=0.0003 \\
P_{1-3}=0.0001 \\
P_{2-3}=0.064\end{array}$ \\
\hline Glucose, $\mathrm{mmol} / \mathrm{L}$ & $4.25 \pm 0.12$ & $6.58 \pm 1.12$ & $7.60 \pm 3.85$ & $8.20 \pm 1.23$ & $\begin{array}{l}P_{1-2}=0.00002 \\
P_{1-3}=0.00003 \\
P_{2-3}=0.14\end{array}$ \\
\hline $\mathrm{HbA1c}(\%)$ & $4.60 \pm 0.02$ & $6.50 \pm 0.01$ & $7.10 \pm 0.50$ & $9.20 \pm 0.60$ & $\begin{array}{l}P_{1-2}=0.0006 \\
P_{1-3}=0.0003 \\
P_{2-3}=0.035\end{array}$ \\
\hline GTT, $\mathrm{mmol} / \mathrm{L}$ & $5.12 \pm 0.04$ & $6.16 \pm 0.05$ & $11.34 \pm 0.40$ & $14.80 \pm 2.10$ & $\begin{array}{l}P_{1-2}=0.0004 \\
P_{1-3}=0.0002 \\
P_{2-3}=0.054\end{array}$ \\
\hline
\end{tabular}

SD: standard deviation; IR: insulin resistance; AH: arterial hypertension; type 2 DM: type 2 diabetes mellitus; HOMA-IR: homeostatic model assessment for insulin resistance; CRP: C-reactive protein; HbA1c: glycated hemoglobin; GTT: glucose tolerance test

Table 2: Hemodynamic parameters in surveyed groups of patients

\begin{tabular}{|c|c|c|c|c|}
\hline Indexes & $\begin{array}{l}\text { Control } \\
(n=20)\end{array}$ & $\begin{array}{c}\text { AH } \\
(n=32)\end{array}$ & $\begin{array}{c}\text { AH + pre-diabetes } \\
(n=30)\end{array}$ & $\begin{array}{c}\mathrm{AH}+\underset{\text { type } 2 \mathrm{DM}}{(n=33)}\end{array}$ \\
\hline $\mathrm{SBP}, \mathrm{mmHg}$ & $125.30 \pm 4.40$ & $158.70 \pm 3.20^{*}$ & $173.90 \pm 4.60^{*, \#}$ & $185.40 \pm 4.80^{\$}$ \\
\hline $\mathrm{DBP}, \mathrm{mmHg}$ & $81.80 \pm 5.60$ & $90.20 \pm 5.30^{*}$ & $98.50 \pm 8.20^{*, \#}$ & $105.20 \pm 9.30^{\$}$ \\
\hline LASPh, $\mathrm{cm}$ & $2.72 \pm 0.09$ & $2.82 \pm 0.90$ & $3.25 \pm 0.05^{\star, \#}$ & $3.64 \pm 0.07^{\$}$ \\
\hline $\mathrm{EDV}, \mathrm{cm}^{3}$ & $129.00 \pm 1.16$ & $135.24 \pm 1.16$ & $141.10 \pm 1.15^{*, \#}$ & $144.20 \pm 1.13^{\#}$ \\
\hline $\mathrm{ESV}, \mathrm{cm}^{3}$ & $47.40 \pm 0.30$ & $48.10 \pm 0.40$ & $61.20 \pm 0.80^{*, \#}$ & $78.40 \pm 0.60^{\$}$ \\
\hline $\mathrm{EDD}, \mathrm{cm}^{3}$ & $4.62 \pm 0.02$ & $5.16 \pm 0.04^{*}$ & $5.35 \pm 0.06^{*, \#}$ & $5.56 \pm 0.08^{\#}$ \\
\hline ESD LV, cm & $4.12 \pm 0.04$ & $4.18 \pm 0.04$ & $3.55 \pm 0.03^{*}$ & $3.96 \pm 0.04^{\#}$ \\
\hline Stroke volume, $\mathrm{cm}^{3}$ & $75.50 \pm 1.27$ & $83.90 \pm 1.36$ & $91.10 \pm 0.74^{*, \#}$ & $97.20 \pm 0.72^{\#}$ \\
\hline Ejection fraction, \% & $65.40 \pm 0.86$ & $66.80 \pm 0.74$ & $52.90 \pm 0.42^{*}$ & $54.80 \pm 0.44^{\#}$ \\
\hline Myocardium mass index $\mathrm{LV}, \mathrm{g} / \mathrm{m}^{2}$ & $81.60 \pm 0.02$ & $98.60 \pm 0.03$ & $116.40 \pm 1.42^{*, \#}$ & $143.40 \pm 1.36^{\#, \$}$ \\
\hline
\end{tabular}

${ }^{*} P<0.05$ vs. control group; ${ }^{\#} P<0.05$ vs. AH patients; ${ }^{\$} P<0.05$ vs. patients with $\mathrm{AH}$ and pre-diabetes. AH: arterial hypertension; type 2 DM: type 2 diabetes mellitus; SBP: systolic blood pressure; DBP: diastolic blood pressure; LASPh: left atrial systole phase; EDV: enddiastolic volume; ESV: end-systolic volume; EDD: end-diastolic dimension; ESD: end-systolic dimension; LV: left ventricular

0.046), and HOMA-IR $(P=0.044)$. Patients from group 2 in $12.3 \%$ of cases, and in $38.7 \%$ of cases from group 3 were marked as having atherosclerotic plaques with a degree of stenosis $<10 \%$.

LVH was diagnosed in $92.3 \%$ of patients from group 3 , $75.8 \%$ of patients from group 2 , and $55.4 \%$ of patients from group 1, compared to the controls $(P<0.05)$. Patients with $\mathrm{AH}$ and type $2 \mathrm{DM}$ were characterized by an increase of average LVMM $(P<0.05)$ and LVMMI values $(P<0.05)$ compared with patients in group 1 , group 2, and the control group. Indices of Doppler echography intracardiac hemodynamics in patients with $\mathrm{AH}$ were characterized by a decrease in the early and late diastolic filling rate of LV [Table 2]. However, under the concomitant conditions of disease in groups 2 and 3 , these indexes were significantly reduced compared to group 1 and the control group $(P<0.05)$. Similar patterns were observed in the ratio of the early and late diastolic filling velocities.

Also, the maximum ESD LV and EDD LV values were registered in patients of group 3 in comparison with group 1 and control $(P<0.05)$ and a pattern of increase in these indicators was observed in group 2. The same situation was observed with respect to ESV LV and EDV LV $(P<0.05)$. Patients in groups 2 and 3 with concomitant disease had a significant increase of MMI relative to group $1(P<0.05)$.

Levels of $\mathrm{Gal}-3$ were heightened in patients concomitant $\mathrm{AH}$ and type $2 \mathrm{DM}$ compared to groups 1 and 2, and the control group $(34.2 \mathrm{ng} / \mathrm{mL}$ compared to $27.6 \mathrm{ng} / \mathrm{mL}$, $25.8 \mathrm{ng} / \mathrm{mL}, 15.6 \mathrm{ng} / \mathrm{mL}$ respectively, $P<0.001)$.

In patients with $\mathrm{AH}$ and pre-diabetes we observed a trend towards a positive correlation between Gal-3, CRP, and HOMA-IR, which is most marked in patients 
with $\mathrm{AH}$ and type $2 \mathrm{DM}[\mathrm{Gal}-3, \mathrm{CRP}(r=0.52, P<$ $0.01)$, and HOMA-IR $(r=0.62, P<0.01)]$.

In patients with concomitant $\mathrm{AH}$ and type $2 \mathrm{DM}$ there was a positive correlation between Gal-3 and the IMT CCA $(r=0.44, P<0.001)$. It is should be noted that in patients with isolated $\mathrm{AH}$ and in patients of groups 2 and 3 having LVH, Gal-3 levels were significantly higher than in patients without LVH $(P<0.05)$.

\section{DISCUSSION}

The study found patients from group 3 to have the highest insulin and C-peptide values, suggesting that the progression of IR under hyperinsulinemia is associated with the presence of type 2 diabetes.

Identified correlations between insulin and LVH and IMT CCA in patients from groups 2 and 3 , suggest that hyperinsulinemia is an important component for the development and progression of $\mathrm{AH}$ and contributes to the development of myocardial hypertrophy and smooth muscle elements of peripheral vessels.

Further observation is necessary in patients from groups 2 and 3 with identified atherosclerotic plaques of stenosis grade exceeding $10 \%$. It should be noted that current results are concordant with the Insulin Resistance Atherosclerosis Study, which revealed a clear direct dependence between the degree of insulin resistance and the carotid artery wall thickness both in individuals without diabetes, and in patients with type 2 DM. With each unit of insulin resistance, IMT increased by $30 \mu \mathrm{m} .{ }^{[22]}$ Similar conclusions were obtained in an analysis of the results of 11 studies, involving 1578 patients with type $2 \mathrm{DM}$, including 132 patients with pre-diabetes who developed IMT CCA index during the treatment. ${ }^{[23]}$ It was found that un-treated patients with type $2 \mathrm{DM}$ had an average content of $\mathrm{HbA} 1 \mathrm{c}=7.86 \%$, and an increase in IMT CCA by $0.034 \mathrm{~mm}$ per year. ${ }^{[24]}$ This reveals significant dependence between $\mathrm{HbA} 1 \mathrm{c}$ levels and the rate of IMT CCA increase. ${ }^{[24]}$

Patients of group 2 with concomitant $\mathrm{AH}$ presented with structural-functional and intraventricular hemodynamic changes, changes that were most apparent in group 3.

As to the mechanisms of $\mathrm{LVH}$ in $\mathrm{AH}$ patients with type 2 DM, we should mention a complex of metabolic disorders which are typical for type 2 DM. ${ }^{[25]}$ Those disorders primary include insulin resistance and hyperinsulinemia. Indeed, insulin resistance and hyperinsulinemia are triggers that induce a series of hormonal, neurohumoral and metabolic events that are the basis of early LVH in concomitant $\mathrm{AH}$ and type 2
$D M{ }^{[26]}$ This process is largely a result of activation of the sympathetic-adrenal system, a powerful stimulus for renin and angiotensin II excretion with a consequent increase of aldosterone production and development of the hyperkinetic, hyper-renin variant of hypertension. ${ }^{[27]}$ Powerful hypertrophic and proliferative processes in the myocardium are triggered accompanied by volume overload of the heart, which leads to LVH in patients with $\mathrm{AH}$ and type $2 \mathrm{DM}$. The most important proliferative and hypertrophic factors involved in the processes of myocardial hypertrophy include a number of cytokines and other growth factors. ${ }^{[25]}$

It has been observed that Gal-3 levels are positively correlated with insulin resistance indices (CRP, HOMA) in all groups of patients. These data confirm that Gal3 is involved in the formation of insulin resistance. In this study, higher levels of Gal-3 are associated with the development of type $2 \mathrm{DM}$. The obtained results substantiate the study of Seferovic et al.. ${ }^{[28]}$ which describes elevated levels of Gal-3 in patients with type $2 \mathrm{DM}$ that were strongly correlated with $\mathrm{HbA} 1 \mathrm{c}$ levels. Yilmaz et al. ${ }^{[29]}$ showed that Gal-3 may be an independent predictor of type $2 \mathrm{DM}$ in general. Recent clinical studies have shown that high levels of Gal-3 correlate with gender, age, and the risk of cardiovascular pathology development. ${ }^{[30]}$ On the other hand, the study of Ohkura et al. ${ }^{[31]}$ found that low levels of serum Gal-3 are associated with insulin resistance in patients with type $2 \mathrm{DM}$, but it should be noted that a small sample of patients were examined with no comorbid pathology and a BMI within the normal range.

Gal-3 values were positively correlated with LVH and increased indices of IMT CCA. These data are consistent with available literature showing that Gal-3 increases its activity under the influence of such factors as increased levels of angiotensin II and pressure overload of the myocardial wall. References contain some data identifying a correlation of GAL-3 and the total number of atherosclerosis plaques in coronary arteries. $^{[32]}$ It can be assumed that Gal-3 levels may be a marker for the major pathogenetic mechanisms of development and progression of atherosclerosis, which can help the early detection of atherosclerosis before its clinical manifestations. Also, increasing serum Gal3 levels may help to identify early heart failure with preserved LV ejection fraction, which often occurs in patients with hypertension, diabetes, and obesity. ${ }^{[33]}$

The above results indicate that elevated levels of Gal3 in the blood plasma can be a predictor of type 2 $\mathrm{DM}$, and factor in the development of structural and functional changes in the myocardium. Nevertheless, these findings require further study on a large sample 
of patients, taking into account gender differences and duration of comorbid pathology.

In conclusion, chronic hyperglycemia and insulin resistance affected the cardiovascular remodeling of the myocardium and blood vessels, which was mostly observed in the concomitant $\mathrm{AH}$ and type $2 \mathrm{DM}$ patients.

This study makes it possible to assume that Gal3 is involved in the processes of insulin resistance progression and cardiovascular remodeling in patients with isolated hypertension and patients with hypertension and type $2 \mathrm{DM}$.

In order to gain a clearer understanding of the Gal-3 role in the pathogenesis of hypertension and type 2 $\mathrm{DM}$, the larger clinical trial needs to be conducted.

\section{Authors' contributions}

L. Bobronnikova contributed solely to this paper.

\section{Financial support and sponsorship}

None.

\section{Conflicts of interest}

There are no conflicts of interest.

\section{Patient consent}

All the patients signed an informed consent agreement to participate in the research.

\section{Ethics approval}

The study protocol was approved by the Local Ethics Committee of the Kharkov National Medical University and was performed in accordance to the Declaration of Helsinki.

\section{REFERENCES}

1. Mancia G, Fagard R, Narkiewicz K, Redón J, Zanchetti A, Böhm M, Christiaens T, Cifkova R, De Backer G, Dominiczak A, Galderisi M, Grobbee DE, Jaarsma T, Kirchhof P, Kjeldsen SE, Laurent S, Manolis AJ, Nilsson PM, Ruilope LM, Schmieder RE, Sirnes PA, Sleight P, Viigimaa M, Waeber B, Zannad F; Task Force Members. 2013 ESH/ ESC Guidelines for the management of arterial hypertension: the Task Force for the management of arterial hypertension of the European Society of Hypertension (ESH) and of the European Society of Cardiology (ESC). J Hypertens 2013;31:281-357.

2. Fox CS, Coady S, Sorlie PD, Levy D, Meigs JB, D’Agostino RB Sr, Wilson PW, Savage PJ. Trends in cardiovascular complications of diabetes. JAMA 2004;292:2495-9.

3. Aroor AR, Mandavia CH, Sowers JR. Insulin resistance and heart failure: molecular mechanisms. Heart Fail Clin 2012;8:609-17.

4. Huxley R, Barzi F, Woodward M. Excess risk of fatal coronary heart disease associated with diabetes in men and women: meta-analysis of
37 prospective cohort studies. $B M J$ 2006;332:73-8.

5. Blacher J, Staessen JA, Girerd X. Pulse pressure not mean pressure determines cardiovascular risk in older hypertensive patients. Arch Intern Med 2000;160:1085-9.

6. Rydén L, Standl E, Bartnik M, Van den Berghe G, Betteridge J, de Boer MJ, Cosentino F, Jönsson B, Laakso M, Malmberg K, Priori S, Ostergren J, Tuomilehto J, Thrainsdottir I, Vanhorebeek I, StrambaBadiale M, Lindgren P, Qiao Q, Priori SG, Blanc JJ, Budaj A, Camm J, Dean V, Deckers J, Dickstein K, Lekakis J, McGregor K, Metra M, Morais J, Osterspey A, Tamargo J, Zamorano JL, Deckers JW, Bertrand M, Charbonnel B, Erdmann E, Ferrannini E, Flyvbjerg A, Gohlke H, Juanatey JR, Graham I, Monteiro PF, Parhofer K, Pyörälä K, Raz I, Schernthaner G, Volpe M, Wood D; Task Force on Diabetes and Cardiovascular Diseases of the European Society of Cardiology (ESC); European Association for the Study of Diabetes (EASD). Guidelines on diabetes, pre-diabetes, and cardiovascular diseases: executive summary. The Task Force on Diabetes and Cardiovascular Diseases of the European Society of Cardiology (ESC) and of the European Association for the Study of Diabetes (EASD). Eur Heart $J$ 2007;28:88-136.

7. Schillaci G, Verdecchia P, Porcellati C, Cuccurullo O, Cosco C, Perticone F. Continuous relation between left ventricular mass and cardiovascular risk in essential hypertension. Hypertension 2000;35:580-6.

8. Vakili BA, Okin PM, Devereux RB. Prognostic implications of left ventricular hypertrophy. Am Heart J 2001;141:334-41.

9. Ho JE, Liu C, Lyass A, Courchesne P, Pencina MJ, Vasan RS, Larson MG, Levy D. Galectin-3, a marker of cardiac fibrosis, predicts incident heart failure in the community. J Am Coll Cardiol 2012;60:1249-56.

10. de Boer RA, van Veldhuisen DJ, Gansevoort RT, Muller Kobold AC, van Gilst WH, Hillege HL, Bakker SJ, van der Harst P. The fibrosis marker galectin-3 and outcome in the general population. J Intern Med 2012;272:55-64

11. van der Velde AR, Gullestad L, Ueland T, Aukrust P, Guo Y, Adourian A, Muntendam P, van Veldhuisen DJ, de Boer RA. Prognostic value of changes in galectin-3 levels over time in patients with heart failure: data from CORONA and COACH. Circ Heart Fail 2013;6:219-26.

12. Barrow H, Rhodes JM, Yu LG. Simultaneous determination of serum galectin-3 and -4 levels detects metastases in colorectal cancer patients. Cell Oncol (Dordr) 2013;36:9-13.

13. Vereecken P, Awada A, Suciu S, Castro G, Morandini R, Litynska A, Lienard D, Ezzedine K, Ghanem G, Heenen M. Evaluation of the prognostic significance of serum galectin-3 in American Joint Committee on Cancer stage III and stage IV melanoma patients. Melanoma Res 2009;19:316-20.

14. McCullough PA, Olobatoke A, Vanhecke TE. Galectin-3: a novel blood test for the evaluation and management of patients with heart failure. Rev Cardiovasc Med 2011;12:200-10.

15. Mensah-Brown EP, Al Rabesi Z, Shahin A, Al Shamsi M, Arsenijevic N, Hsu DK, Liu FT, Lukic ML. Targeted disruption of the galectin-3 gene results in decreased susceptibility to multiple low dose streptozotocin-induced diabetes in mice. Clin Immunol 2009;130:838 .

16. Pejnovic NN, Pantic JM, Jovanovic IP, Radosavljevic GD, Milovanovic MZ, Nikolic IG, Zdravkovic NS, Djukic AL, Arsenijevic NN, Lukic ML. Galectin-3 deficiency accelerates high-fat dietinduced obesity and amplifies inflammation in adipose tissue and pancreatic islets. Diabetes 2013;62:1932-44.

17. Saksida T, Nikolic I, Vujicic M, Nilsson UJ, Leffler H, Lukic ML, Stojanovic I, Stosic-Grujicic S. Galectin-3 deficiency protects pancreatic islet cells from cytokine-triggered apoptosis in vitro. $J$ Cell Physiol 2013;228:1568-76.

18. Darrow AL, Shohet RV, Maresh JG. Transcriptional analysis of the 
endothelial response to diabetes reveals a role for galectin-3. Physiol Genomics 2011;43:1144-52.

19. Karlsen AE, Størling ZM, Sparre T, Larsen MR, Mahmood A, Størling J, Roepstorff P, Wrzesinski K, Larsen PM, Fey S, Nielsen K, Heding P, Ricordi C, Johannesen J, Kristiansen OP, Christensen UB, Kockum I, Luthman H, Nerup J, Pociot F. Immune-mediated beta-cell destruction in vitro and in vivo-a pivotal role for galectin-3. Biochem Biophys Res Commun 2006;344:406-15.

20. Pugliese G, Iacobini C, Ricci C, Blasetti Fantauzzi C, Menini S. Galectin-3 in diabetic patients. Clin Chem Lab Med 2014;52:1413-23.

21. Matthews DR, Hosker JP, Rudenski AS, Naylor BA, Treacher DF, Turner RC. Homeostasis model assessment: insulin resistance and beta-cell function from fasting plasma glucose and insulin concentrations in man. Diabetologia 1985;28:412-9.

22. Haffner SM, Lehto S, Rönnemaa T, Pyörälä K, Laakso M. Mortality from coronary heart disease in subjects with type 2 diabetes and in nondiabetic subjects with and without prior myocardial infarction. $N$ Engl J Med 1998;339:229-34.

23. Yokoyama H, Katakami N, Yamasaki Y. Recent advances of intervention to inhibit progression of carotid intima-media thickness in patients with type 2 diabetes mellitus. Stroke 2006;37:2420-7.

24. Wang H, Yu M, Ochani M, Amella CA, Tanovic M, Susarla S, Li JH, Wang H, Yang H, Ulloa L, Al-Abed Y, Czura CJ, Tracey KJ. Nicotinic acetylcholine receptor alpha7 subunit is an essential regulator of inflammation. Nature 2003;421:384-8.

25. Thakur V, Richards R, Reisin E. Obesity, hypertension, and the heart. Am J Med Sci 2001;321:242-8.

26. Kahn BB, Flier JS. Obesity and insulin resistance. J Clin Invest
2000;106:473-81.

27. du Cailar G, Pasquié JL, Ribstein J, Mimran A. Left ventricular adaptation to hypertension and plasma renin activity. J Hum Hypertens 2000;14:181-8.

28. Seferovic JP, Lalic NM, Floridi F, Tesic M, Seferovic PM, Giga V, Lalic K, Jotic A, Jovicic S, Colak E, Salerno G, Cardelli P, Di Somma S. Structural myocardial alterations in diabetes and hypertension: the role of galectin-3. Clin Chem Lab Med 2014;52:1499-505.

29. Yilmaz H, Cakmak M, Inan O, Darcin T, Akcay A. Increased levels of galectin-3 were associated with prediabetes and diabetes: new risk factor? J Endocrinol Invest 201;38:527-33.

30. de Boer RA, van Veldhuisen DJ, Gansevoort RT, Muller Kobold AC van Gilst WH, Hillege HL, Bakker SJ, van der Harst P. The fibrosis marker galectin-3 and outcome in the general population. $J$ Intern Med 2012;272:55-64

31. Ohkura T, Fujioka Y, Nakanishi R, Shiochi H, Sumi K, Yamamoto N, Matsuzawa K, Izawa S, Ohkura H, Ueta E, Kato M, Miyoshi E, Taniguchi S, Yamamoto K. Low serum galectin-3 concentrations are associated with insulin resistance in patients with type 2 diabetes mellitus. Diabetol Metab Syndr 2014;6:106.

32. Ozturk D, Celik O, Satilmis S, Aslan S, Erturk M, Cakmak HA Kalkan AK, Ozyilmaz S, Diker V, Gul M. Association between serum galectin-3 levels and coronary atherosclerosis and plaque burden/ structure in patients with type 2 diabetes mellitus. Coron Artery Dis 2015;26:396-401

33. Meluzín J, Tomandl J. Can biomarkers help to diagnose early heart failure with preserved ejection fraction? Dis Markers 2015;2015:426045 